Illinois State University

ISU ReD: Research and eData

Theses and Dissertations

$12-18-2019$

Interface Of Glass And Topology

Travis Adams

Illinois State University, travis.adams456@gmail.com

Follow this and additional works at: https://ir.library.illinoisstate.edu/etd

Part of the Fine Arts Commons

Recommended Citation

Adams, Travis, "Interface Of Glass And Topology" (2019). Theses and Dissertations. 1195.

https://ir.library.illinoisstate.edu/etd/1195

This Thesis is brought to you for free and open access by ISU ReD: Research and eData. It has been accepted for inclusion in Theses and Dissertations by an authorized administrator of ISU ReD: Research and eData. For more information, please contact ISUReD@ilstu.edu. 


\title{
INTERFACE OF GLASS AND TOPOLOGY
}

\author{
TRAVIS ADAMS
}

27 Pages

Interface of Glass and Topology is a supportive statement for a collection of blown glass sculptures that employ principles of continuous surface topology along with line and color applications to create a perceptual visual experience. These forms address issues of balance and continuity as well as space relationships of both inside to outside and object to self. This supportive statement will discuss topology as a basis for composition and larger questions of interconnectivity with our environment that serves as a guiding theme of my work.

KEYWORDS: Topology; Continuity; Glass; Environment; Space; Form 
INTERFACE OF GLASS AND TOPOLOGY

TRAVIS ADAMS

A Thesis Supportive Statement Submitted in Partial

Fulfillment of the Requirements

for the Degree of

MASTER OF FINE ARTS

Wonsook Kim School of Art

ILLINOIS STATE UNIVERSITY

2020 
(C) 2020 Travis Adams 
INTERFACE OF GLASS AND TOPOLOGY

TRAVIS ADAMS

COMMITTEE MEMBERS:

John Miller, Chair

Tyler Lotz

Jim Mai

Randy Reid 


\section{DEDICATION}

In fond memory of my incredible mentors Joseph "Joey" Burks II and Stephen Powell. 


\section{ACKNOWLEDGEMENTS}

The writer wishes to thank his parents Steve and Michelle Adams for their steadfast support and love, his incredible friends that have and continue to support his glass work and life journey, and the wonderful faculty at Illinois State University who's insight and encouragement made his M.F.A. experience a success. Additionally, a special thank you is extended to committee members Randy Reid, Jim Mai, and Tyler Lotz for their dedication and knowledge, and to John Miller for his guidance, friendship, and shared love of glass.

T.A. 


\section{CONTENTS}

DEDICATION

i

ACKNOWLEDGEMENTS $\quad$ ii

$\begin{array}{lll}\text { CONTENTS } & \text { iii }\end{array}$

FIGURES

INTODUCTION 1

CHAPTER I: BASIS FOR TOPOLOGY 4

CHAPTER II: COMPOSITIONAL ELEMENTS 6

CHAPTER III: INFLUENCE AND APPLICATIONS $\quad 8$

$\begin{array}{ll}\text { CHAPTER IV: VISUAL ANALYSIS } & 10\end{array}$

CHAPTER V: ENLIVENING SPACES 13

$\begin{array}{ll}\text { CONCLUSION } & 15\end{array}$

$\begin{array}{ll}\text { WORKS CITED } & 27\end{array}$ 


\section{FIGURES}

Figure

Page

1. Tuòpū Loop I

17

2. Tuòpū Loop IV

18

3. Tuòpū Loop III

19

4. Construction

5. Topo I

21

6. Topo II

7. Concentric Dilation I

8. Concentric Dilation II

9. Concentric Dilation III

10. Wān yán 


\section{INTRODUCTION}

My work and research have been guided by an unquenchable need to understand our interconnective experience with the natural world and more specifically our subconscious connections with the environment. This large and nuanced topic is worthy of lifelong study, and my work will continue to attend to both the physical and metaphysical elements of Oneness with nature. ${ }^{1}$ While I am most interested in the energetic exchange (physical and psychic) between ourselves and the natural world and the manner in which the environment informs our human experience, I have found that these elusive ideas are best approached and examined concretely through sculptural forms. The paper that follows will address those sculptural manifestations.

This body of blown glass works is rooted in topology and the relationship of continuous surfaces. The category of topology has guided my examination of sculptural forms whose surfaces and openings permit fluid passage between internal and external spaces. These forms encourage a heightened perceptual awareness of connections between inner and outer contexts (metaphorically, etc.), perhaps leading to the point of personal identification. This may permit these sculptures to stimulate thoughts of our own experiences of inner and outer exchange, both physically and psychologically. With that, the following text will explain the implications of topology, fluidity, and balance in this body of glass objects.

As was true for such Concrete artists as Max Bill, this group of blown and hot sculpted glass forms is a departure from reliance on external or natural appearances ${ }^{2}$. This careful

\footnotetext{
${ }^{1}$ Oneness in this instance refers to our active participation in and continuous exchange with nature. That is to say, we do not stand apart as passive observers, but in fact are integrally involved in the living system of the natural world. Just as a drop of rain or singing bird, we give and receive life energy within the environment and by so doing we are made One.

${ }^{2}$ Bill, Max, and Margit Staber. Max Bill. Erker-Verlag, 1971, 23.
} 
decision gives rise to form that is perceptible beyond literal references to natural textures, shapes, or spaces. The forms in this investigation define topologic conditions of space, fluidity, and continuous surfaces that are models for our relationships to the larger world of Nature. That is, elusive ideas of balance, interconnectivity, and collective energy with our environment that exist in our subconscious are made visible. However, these experiences are observed on a conscious level before the glass sculptures are made. For example, the awareness of our body's physical balance or the observation of the peculiar growth of a tree limb draw up these experiences for conscious observation. As Angus Fletcher notes, "In my view these linkages [of disjunctive fields of thought] are virtually all topological, since every encounter with scale and balance will require most humans to think beyond the narrow confines of those little worlds we know "for ourselves." 3

The glass sculptures in question emerge from similar encounters to those Fletcher describes. Though tactical decisions are made in process, the topological form is a visual manifestation of this conscious exercise. Furthermore, Fletcher's notion of "thinking beyond" self makes the topological forms presented in this body of work active models for bringing to the surface the subconscious activity mentioned above. I have embraced the abstraction of topological principles and segmented geometric shapes as a means of providing perceptual emphasis on relationships instead of figurative and textural references to natural phenomena.

I have worked with the latter, and may return to a figurative approach in the future, but I have found my current concerns are best realized in abstract forms. The viewer is thus charged with

\footnotetext{
${ }^{3}$ Fletcher, Angus. The Topological Imagination: Spheres, Edges, and Islands. Harvard University Press., 2016, 4142.
} 
the task of examining explicit moments of balance, continuity, color, and void space that stand apart from factual references to nature. 


\section{CHAPTER I: BASIS FOR TOPOLOGY}

In mathematical terms, topology is defined as "the study of continuous functions". ${ }^{4}$ Some coin this field of mathematics as "rubber sheet geometry" or continuous shape without reference to a measured distance or scale. Most important to the hot sculpted glass objects in this group is the principle of continuity and the combination of void openings in a singular form without surface breaks or angular seams. The series began with an exploration of two closed bands with a contrasting color field representing each surface. The openings within the first sculptures were created with rotational alignment about a vertical axis. The first forms of the series pictured in Figures 1, 2, and 3 outline a few examples of the continuous perceptual loops that may arise from one vantage point, though more continuous linear connections may be drawn when these works are viewed in the round. The sculptures that follow these early works further exploit coloration of the glass material to accentuate the topological activity and challenge the viewer to explore the balance and continuity within each piece.

One might ask: Isn't this mathematics rather than art? Why study topology through visual art? What does this field of mathematics tell us about our experiences and relationship to the natural world? Without knowledge of geometry or topology, can a viewer access the underlying meaning of these forms?

Angus Fletcher begins to answer these questions by suggesting:

"As a mathematical discipline topology makes a deep connection with idealist philosophy and ultimately illuminates ethical thought, and at the same time its

\footnotetext{
${ }^{4}$ Basener, William F. Topology and Its Applications. John Wiley \& Sons Inc, 2006, xxix.
} 
methods animate the most exacting research into fields such as neurophysiology and computer science... The appearance of things is a quality we perceive, and it might be generally stated that topology is concerned with perceived shapes, while geometry is concerned only with measured shapes."

Through this body of work, I have come to agree with Fletcher's claim. These forms embrace fundamentals of topology - stretching, twisting, rotating, opening, without cutting and without respect to measurable scale relationships. This may seem elementary on the surface, but contemplation of these sculptures reveals a major question of how shapes relate to placement in space. It follows that one may examine their own position in space and by extension their continuity within the system of all things. ${ }^{6}$ Thus, topology does link with "idealist philosophy" by way of examining continuity of form with respect to space. The essence, therefore, of this beginning body of glass objects and study of topological principles has far-reaching implications.

\footnotetext{
${ }^{5}$ Fletcher, Angus. The Topological Imagination: Spheres, Edges, and Islands. Harvard University Press., 2016, 11.

6 "All things" captures our malleable position in nature, political systems, families, etc. We adapt with topological principles in these examples by holding position in space or placement within the continuous unit. When the unit is split, say by divorce in the case of families or by building a river dam, the continuity is severed and a new topological structure applies. Nevertheless, these experiences validate Fletcher's statement.
} 


\section{CHAPTER II: COMPOSITIONAL ELEMENTS}

Topology is employed by mathematics and the sciences to describe a range of phenomena, such as cell regeneration, our own cardiovascular system, and modeling data chaos in computer science. Yet topology offers the imagination ways to think about our experience of

and mediation between spaces. The glass sculptures in question were directed by a compositional strategy that permits the examination of two discrete spaces, outside and inside. In the case of Figures 5 and 6, the distinction between these two spaces is described by a change in surface color from reflective blue-green interior to black or white exterior, and the continuous exterior line. Importantly, the openings in these sculptures allow the viewer to explore both spaces simultaneously. This experience relies on the active elements of topology (continuity, opening, stretching, etc.) at work in each of the sculptures in this group.

Figures 5 and 6 also introduce a punctured torus or donut form frequently examined within the field of topology. The central opening is bound by a continuous surface that encloses a tunnel creating its perimeter. The punctures at either end offer windows into the interior space and through the tunnels created by the central torus structure. This mediation of internal and external spaces enlivens the sculpture by presenting form in relationship to the viewer's own position in the world around them. Although we immediately understand we are connected physically to the external environment, it is less clear how this occurs psychologically, spiritually. Perhaps these sculptures can point towards the topology of connection between our psyche and nature.

Matthias Bruhn writes in The Islands of Benoit Mandelbrot that humans have been fixed on the issue of chaos while seeking a visual language of order and balance. He points to topics of anarchy and political unrest as only one example of many concerning the absence of order in 
human interaction. Further, Bruhn writes, "for millennia, the dialectic of order and chaos has repeatedly brought forth new pictorial forms designed to find a logical place for every part of creation." While chaos is not of particular concern of this investigation, it is the use and study of topology that has led to a greater understanding of order within disorder or as Bruhn describes, "envisioning the invisible". ${ }^{7}$ Figure 10 asserts a similar idea by creating a balanced visual experience involving two distinct internal and external surfaces with openings positioned in four symmetrical quadrants rotating around the piece. The disordered, but continuous lines floating above the exterior surface juxtaposes the calm topological balance just described. Though issues of social chaos are not obvious in this form, one can examine our human experience of continuous flux by following the line work around the entire object. Topological structure and the advent of continuous functions applicable to many areas of the human condition have provided the artist new methods to visualize such subjects.

\footnotetext{
${ }^{7}$ Samuel, Nina, and Mandelbrot Benoît B. The Islands of Benoit Mandelbrot: Fractals, Chaos, and the Materiality of Thinking ; Yale University Press, 2012, 87.
} 


\section{CHAPTER III: INFLUENCE AND APPLICATIONS}

It is worthwhile noting the particular influence of Swiss artist Max Bill. Bill made plain his opinion that it was possible to create visual art purely on the basis of mathematics. Though my approach to this group of hot sculpted glass forms does not originate entirely in mathematics, the notion that mathematical systems can play an important role in the creative process is perennial. Bill's work helped define Concrete Art, through both his paintings and sculptural work. The early definition of Concrete Art was applied mostly to the two-dimensional painting surface and suggested Concrete Art was distinct from Abstract Art, "because nothing is more concrete, more real than a line, a colour, or a surface." ${ }^{8}$

Most important to this work in blown glass was a study of Bill's sculptural variations on the motif of surface continuity. Figure 4 is one such example of the sculptor's use of endless surface configurations that involve voids and dynamic spatial interaction. In this example, the viewer might interpret the granite construction as a removal of mass from a sphere, thus revealing the smaller void sphere central to the overall form. One may also imagine the combination of symmetrical concave ring-shapes across a tilted axis, as outlined in yellow in Figure 4. This combination of curved or folded forms builds a sense of continuity within the piece. Additionally, there is a feeling of tension between these shapes as they seem to interlock but are restricted by the diagonal axes and the rotational symmetry. By combining curves created along the edges of the concave ring-shapes, as presented by the blue line segment $A B$ in Figure 4 , one might perceive a moment of continuity created by the sculptor's combination of topological elements. These compositional decisions include the convex sphere, an internal void sphere

\footnotetext{
${ }^{8}$ Bill, Max, and Hüttinger Eduard. Max Bill. Rizzoli International Publications, Inc., 1978, 15.
} 
created by a spatial relationship with concave surfaces, and four circle openings that mediate outside and inside. It is these interlocking tensions and attention to surface relations that opened the way to my own glass forms. 


\section{CHAPTER IV: VISUAL ANALYSIS}

I do not claim to have committed fully to the mathematical and geometric rigor of Concrete Art, but I have embraced a reliance on color, line, and surface as visual cues that enable a perceptual experience of the content described within Section I. By adapting strategies used by artists such as Max Bill, Hans Arp, Barbara Hepworth, Richard Deacon, and Naum Gabo, the hot sculpted objects in this group do not rely on figurative cues such as tree bark texture or illustrated subject matter. Rather, they engage the viewer in a meditative study of space and continuity. Flow, balance, and interconnectivity are suggested by these forms through the use of high-contrast color surfaces that reinforce the topological activity and void openings between external and internal spaces. For example, the color work in Figure 9 exaggerates the expansion of the surface openings and, in effect, freezes the stretching gesture that occurs in the glass making process.

One may compare the figure-eight outline about the $A B$ axis in Figure 1 with the loop relationships present in Max Bill's sculpture in Figure 4. The material weight of these glass forms is lifted by the empty spaces and interior void surrounded by a contrasting color surface. This is both a physical characteristic of the object and a perceptual or intuitive feeling of weightlessness that belies the physical properties of a closed glass form. The viewer may follow the figure-eight outline as in Figure 1 by connecting the interior and exteriors surfaces or by perceptualizing the continuous looping shape of the exterior surface. Both surfaces are thus simultaneously activated providing the feeling of collective energy or Oneness described in the Introduction. The object, with two distinct surfaces and two distinct spaces (outside and inside) is made one through the perceptible interconnectivity - the two are made one in the mind of the viewer. 
Figure 3 provides another example from this group that involves a composition of a simple loop with four openings that twists ninety degrees at the middle, making the reverse S-curve labeled $A B$. From this perspective, the $\mathrm{S}$-curve created by the shape of the internal surface provides an axis of symmetry labeled $C D$. The flowing characteristics of hot sculpted glass take away any rigid tension between the internal and external spaces that might otherwise limit the interplay between the internal S-curve, perceptible axis, and continuous exterior surface. Embracing this visual element, the work possesses a softness that encourages movement and connection between the internal and external environments. The axial alignments provide the sculpture a sense of lift that denies the laws of gravity that would be expected to impact materials with such fluid qualities. These technical decisions help to build concrete meaning into the sculpture and captures the internal-external energetic impact the pieces have within the threedimensional space.

Though the alignments about an axis are not central to the pieces in Figure 5-8, all share a sense of lift that draws the form upward, countering the heavy realities of gravity. The relationship of the openings not only permit the viewer into the interior of the forms but also offer space for an interpretive feeling of malleability. The verticality and proportion of space activated by the forms evoke relationships to the human body. This quality provides a platform for examination of our own topology and position in the space around us.

Figures 7, 8, and 9 utilize a repeated color pattern, with the base unit composed of a central color circle enclosed by a series of concentric color bands. The void openings in the surface of each piece are created by piercing through the central color circle when the glass is hot and malleable, and stretching the element into an additional band. Each sculpture has at least one undisturbed base unit. This not only provides a perceivable constant on the glass surface from 
one to the other but also reflects the topological activity of the overall form. This color application seeks to define the openings while creating a fluid map to follow while observing the continuous glass surface. Transparency, in this case, permits the viewer an additional window to see both internal and external spaces simultaneously. One might note that the distinction between the two spaces is not created by the composition of two solid, contrasting color surfaces. Instead, the sculptures in Figures $7-9$ rely on the physical openings to suggest a delineation between inside and out. One might assume the surfaces are the same given the pattern is transmitted to both sides of the glass. However, one could imagine that to be inside the form looking out provides an entirely different experience of the topology than the exterior perspective. Furthermore, these objects are specifically concerned with the activation of spaces. This is achieved by the shifting color bands affected by the optics of the glass material, changing proportions of the base color units, and the physical windows into and out of the sculpture. The objects seem to hold space within and define the space around which emphasizes the interpretations of topology in our own bodies and position in space. 


\section{CHAPTER V: ENLIVENING SPACES}

In Sculpture and Enlivened Spaces, F. David Martin writes the following regarding the impact of sculpture and its internal and external environment:

"Since the surrounding space is energized by the material body of a sculpture, that space is not only a perceptible part of that sculpture, but it is felt as if it were pushing into and connected with us... Because the enlivened space around a sculpture is continuous with real space, there is also a sense of direct or physical impact... With the exception of sticks and stones striking us, sculpture channels the ordinary impact of things in everyday perception into more concentrated and thus stronger currents. ",9

In an attitude similar to Martin's, my objective in these glass forms is to enliven both internal and external spaces. For me, these formal characteristics are not the ends but the means to tell us about our position within the world. The simultaneous visual experience of the internal and external offers parallels to our experience in the larger environment.

Often, we may assume our perception of an object, a tree for instance, relies solely on factual visual clues (bark, leaves, brown color) all of which are encumbered by previous conditioning of surface information. We begin a sequence of conscious arithmetic, adding limbs, leaves, bark, roots to arrive at the object we call tree. However, this narrow interpretation overlooks an entire, non-physical presence in our

\footnotetext{
${ }^{9}$ Martin, F. David. SCULPTURE AND ENLIVENED SPACE. UNIV. PR. OF KENTUCKY, 1981, 66.
} 
consciousness and our own interconnection with the object being observed. To fully understand the tree is to understand our position in relationship to the tree in space and to the meanings of the tree in our mind.

Another example that reflects the spatial conundrum may be found in the depth of our "knowing" the close personal relations in our lives. We may understand certain behaviors, characteristics, emotions, and histories of people close to us (a spouse for instance), yet we will never gain full knowledge of the individual given the complexities of human nature. From this experience it may be said that we can only observe an external projection of an internal phenomenon (feelings, emotions, thoughts). In this case, we observer internal and external space simultaneously but never in totality.

Similarly, a balance emerges in the glass forms from this discussion. We observe moments of perceptible continuity of two surfaces and windows through internal and external space, but a total visual calculation of the forms is unobtainable. These experiences cause us to assess the placement of self in relationship to the object, loved one, tree, etc. This process aligns with Angus Fletcher's description of topology from Section I. We are constantly involved in topological structures and systems within our environments and the glass objects in this group seek to illuminate that experience through visual perception. 


\section{CONCLUSION}

The continuous surfaces with colors and lines of these works are reflections of our interconnected and unbroken exchange with our environment. Though the forms may be described as two surfaces distinguished by contrasting hues (inner and outer), exterior line detail, concentric color patterning, or some combination, one might also begin to view internal and external spaces contained in one flowing form. This seems a sculptural analogy for our relationship with the natural world and the theme of Oneness addressed in the Introduction. We may imagine that we stand separate from nature, viewing the natural world as functioning independent of self. But we also understand that we are dependent upon natural processes and the larger systems of the natural environment. Independence and dependence coexist in our understanding. Similarly, the two spaces of these sculptures, inner and outer, seem separate but are merely aspects of the same form. They are bound to each other in unity but are capable of momentary separation by our spatial attention and shifting physical and psychological perspectives.

By this interpretation the glass forms are to us as we are to nature. Therefore, the topological approach to visual language in this study is a metaphor, providing the viewer a micro glimpse of structures that impact our daily experiences. In future work I intend to employ more controlled line composition and explore more intentionally the transparent and opaque qualities of the glass medium. The work will further exploit principles of symmetry and shape interactions that shape our perceptual activity. The range of technical exploration in this group of glass objects has established a system of form and color types that are guiding the formation of several series of works I am eager to pursue. Throughout this future exploration I will consider it a worthy task to adapt mathematical 
and geometric modes to the language of glass art as I continue to investigate the essential theme of connectedness to the natural world. 


$$
8
$$




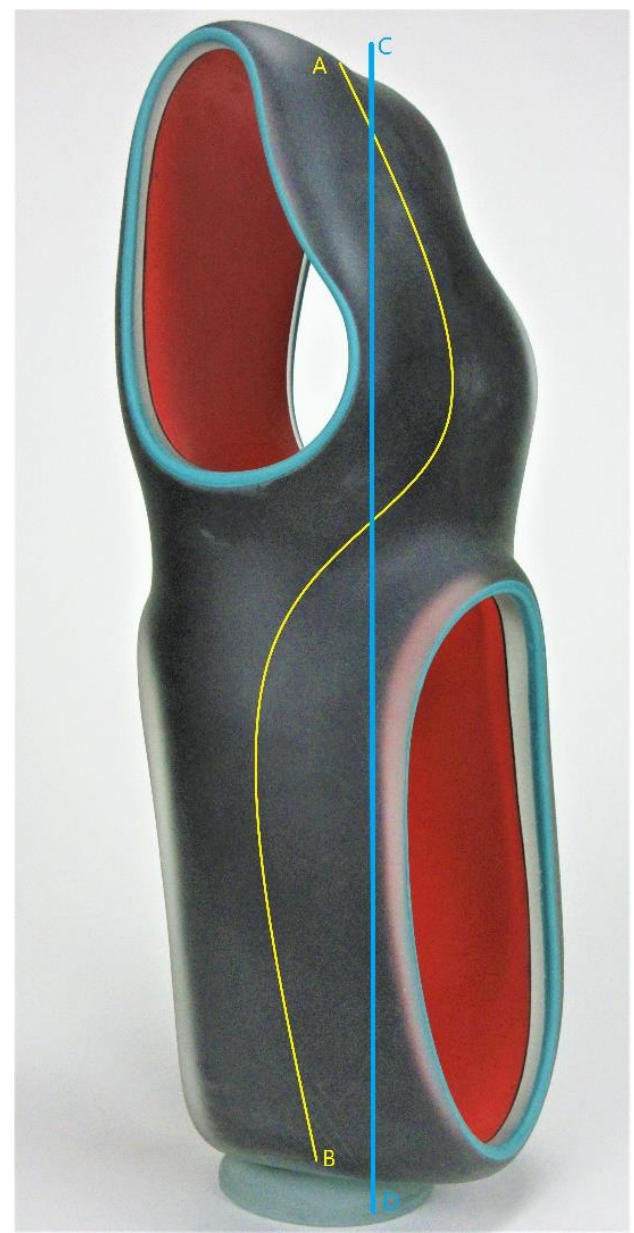

Figure 2. Tuòpū Loop IV, 2019, 17" x 6" x 7" 


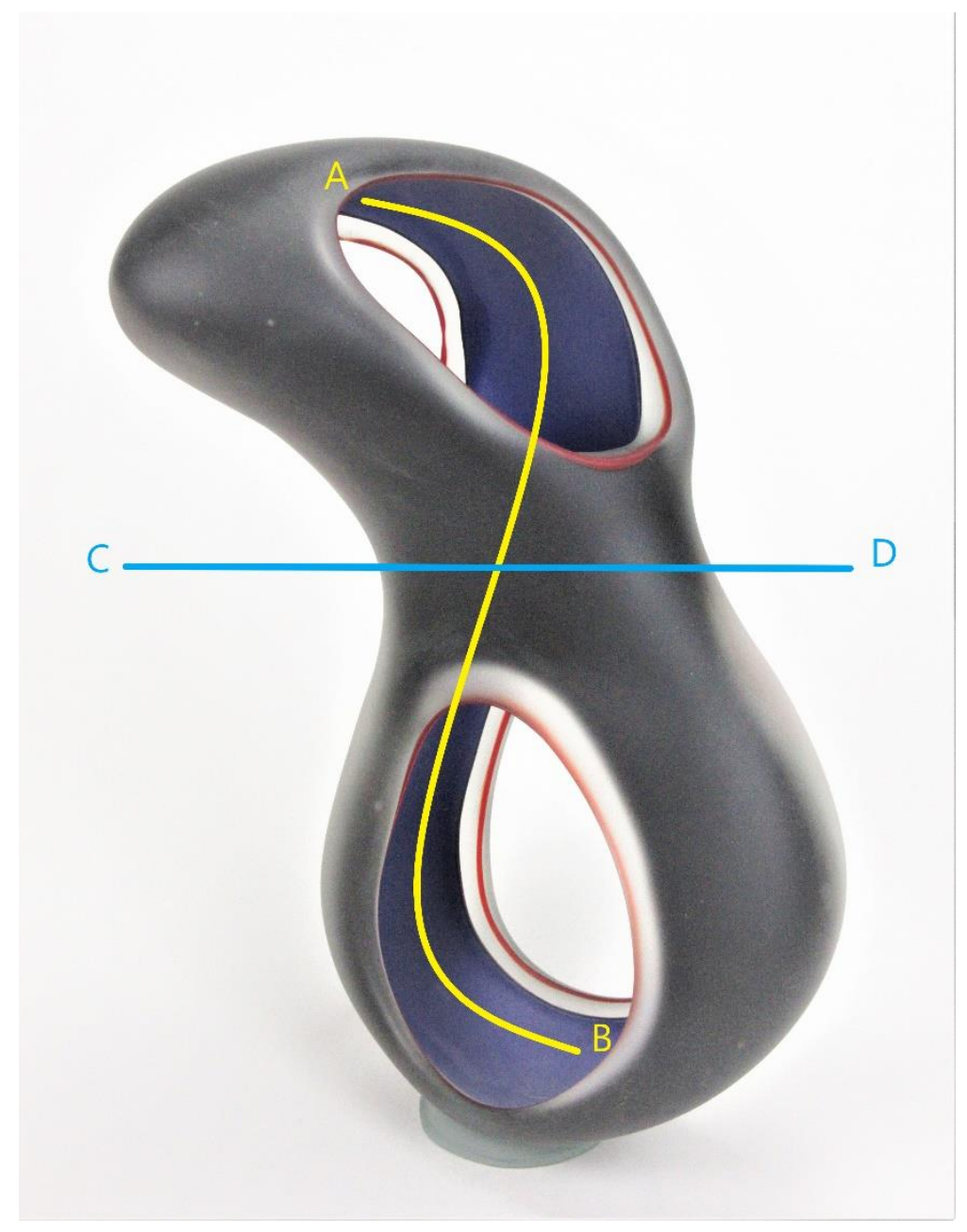

Figure 3. Tuòpū Loop III, 2019, 16" x 10" x 9" 


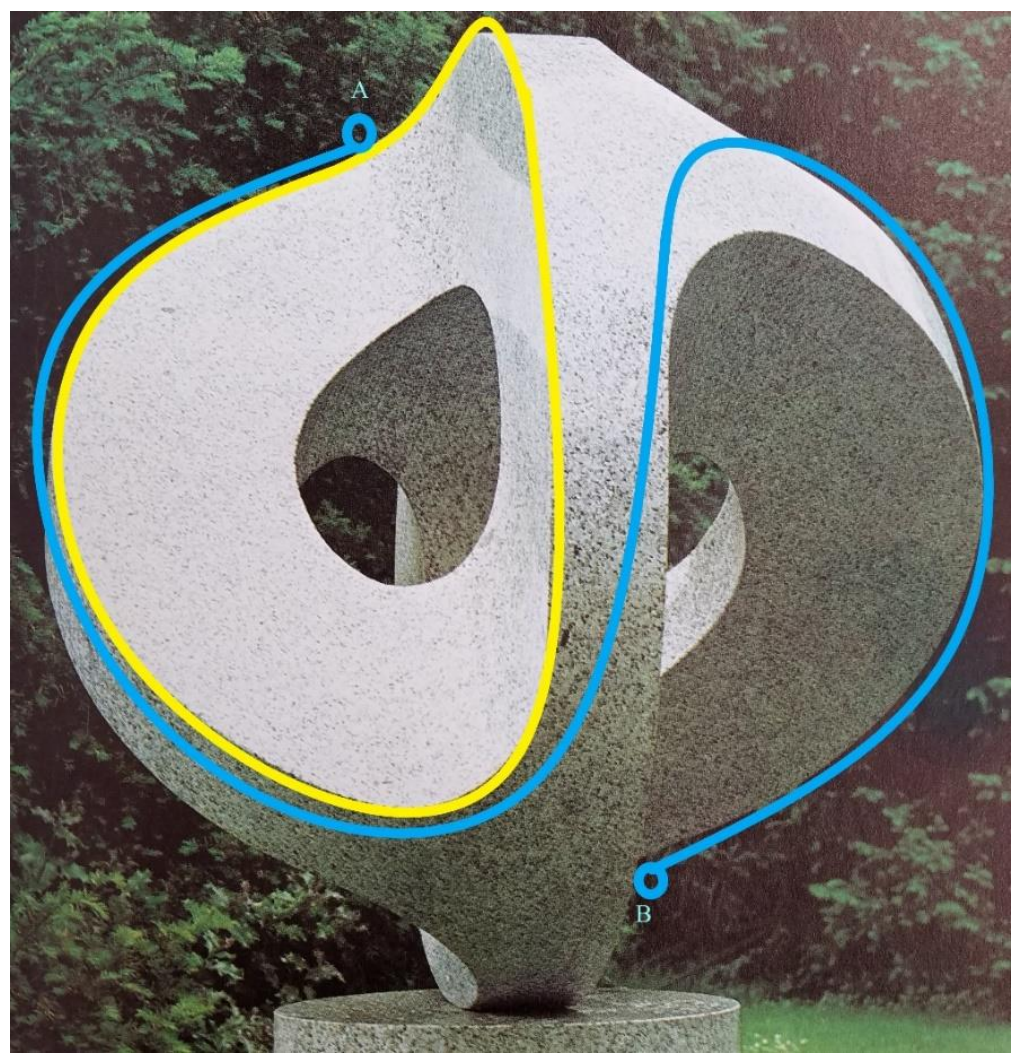

Figure 4. Max Bill, Construction, 1937, grey granite, diameter 471/4”.

Bill, Max, and Hüttinger Eduard. Max Bill. Rizzoli, 1978. 

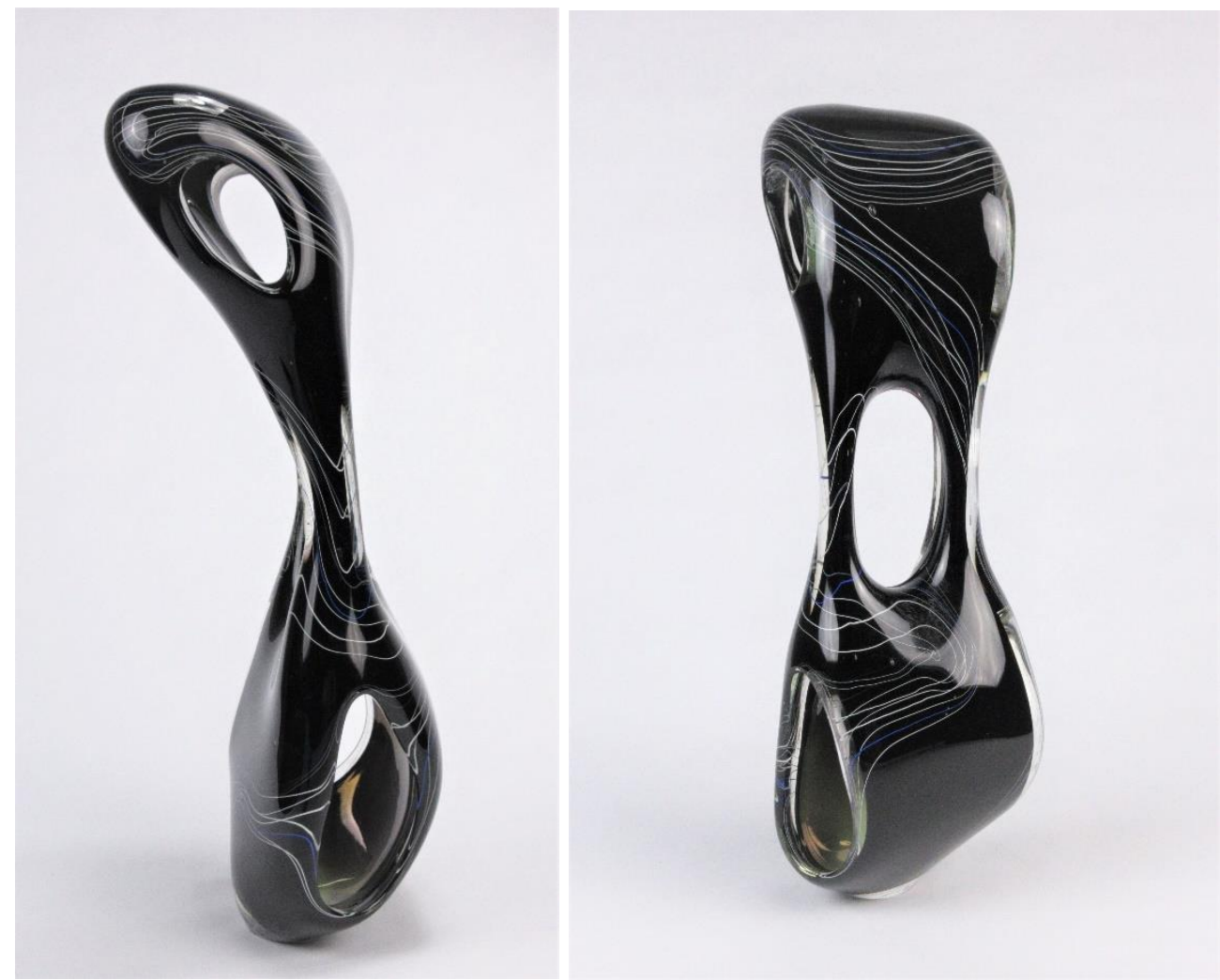

Figure 5. Topo I, 2020, 18" x 7" x 5 1/2" 

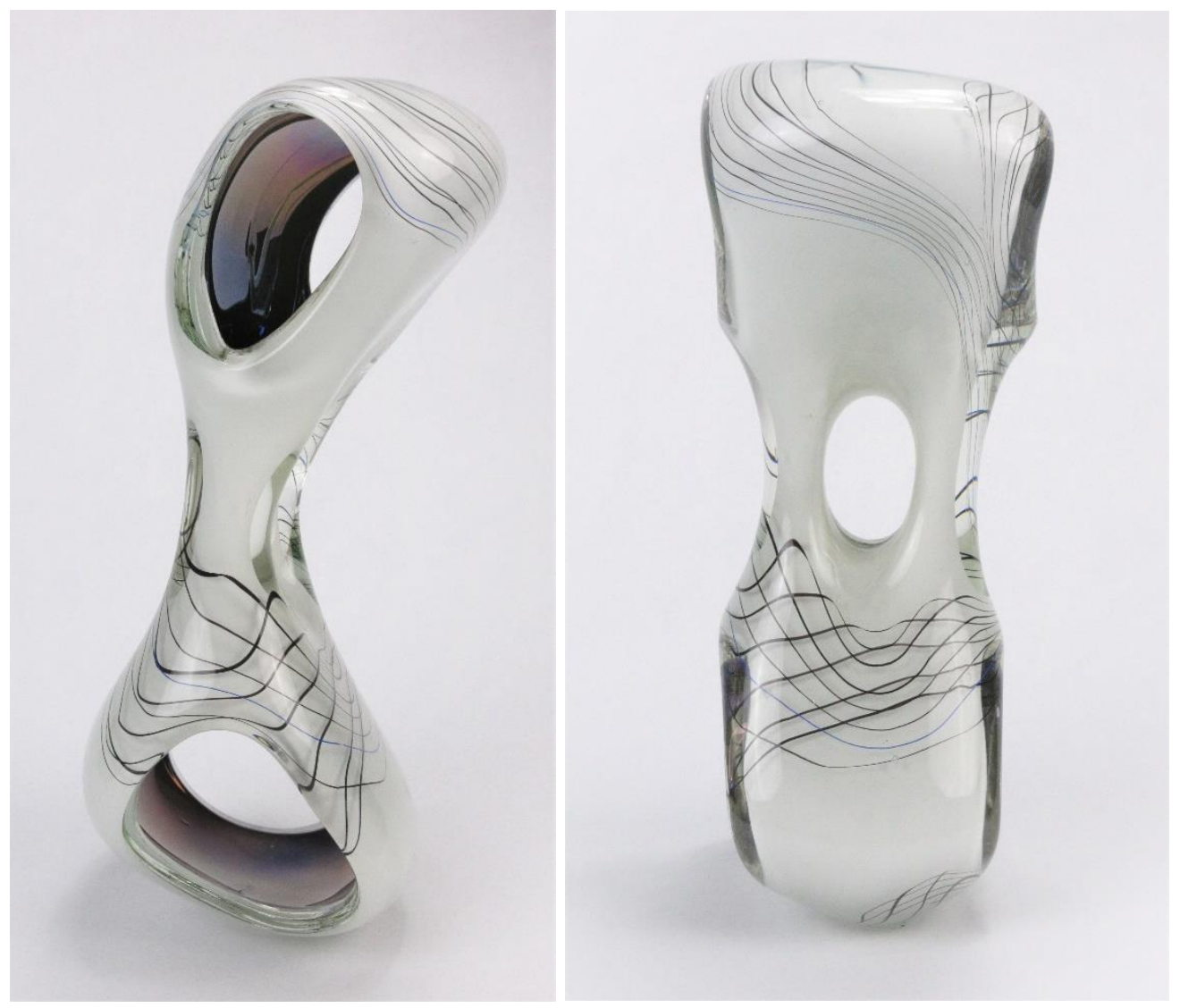

Figure 6. Topo II, 2020, 16" x 6" x 6" 

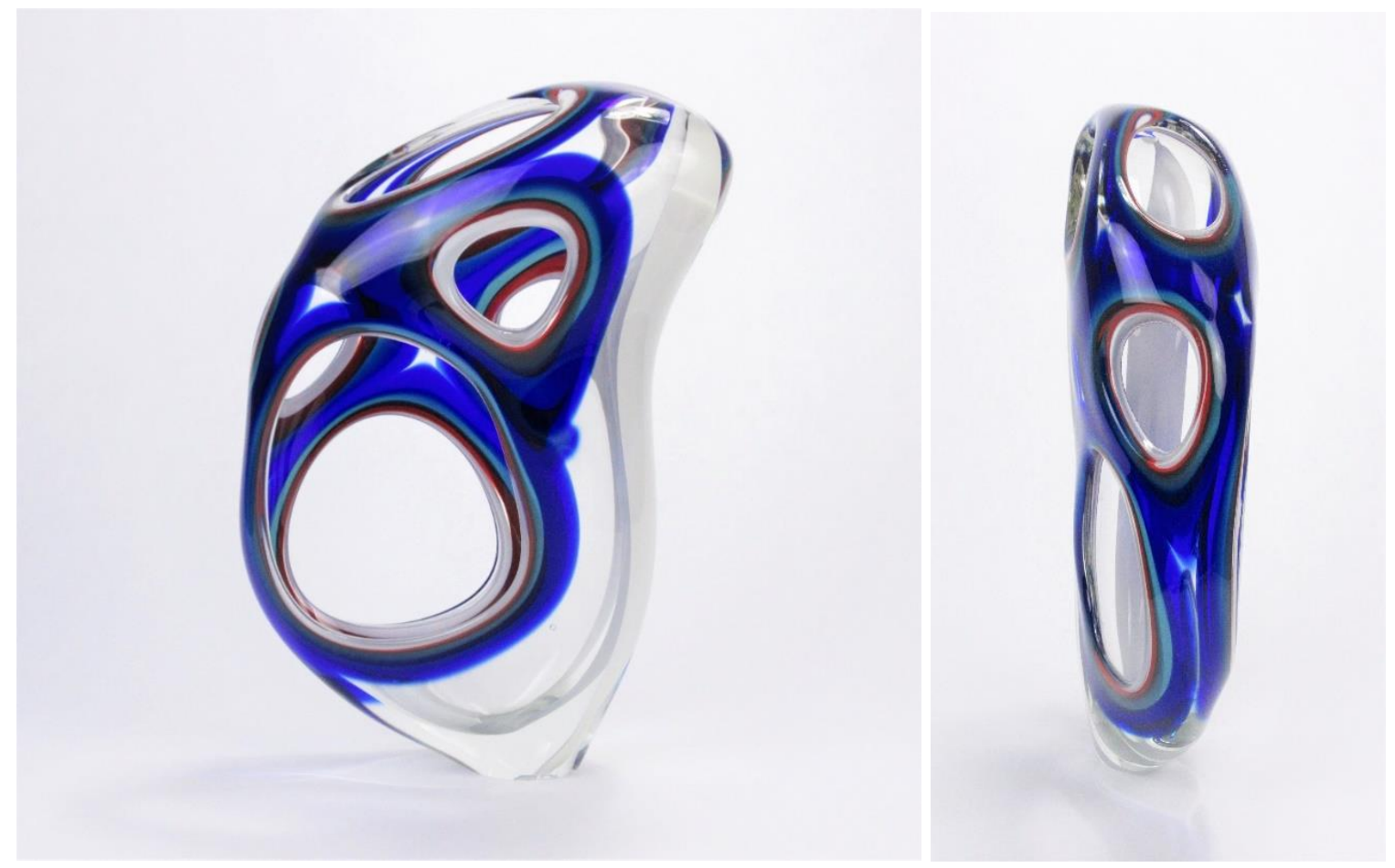

Figure 7. Concentric Dilation I, 2020, 15" x 11" x 5" 


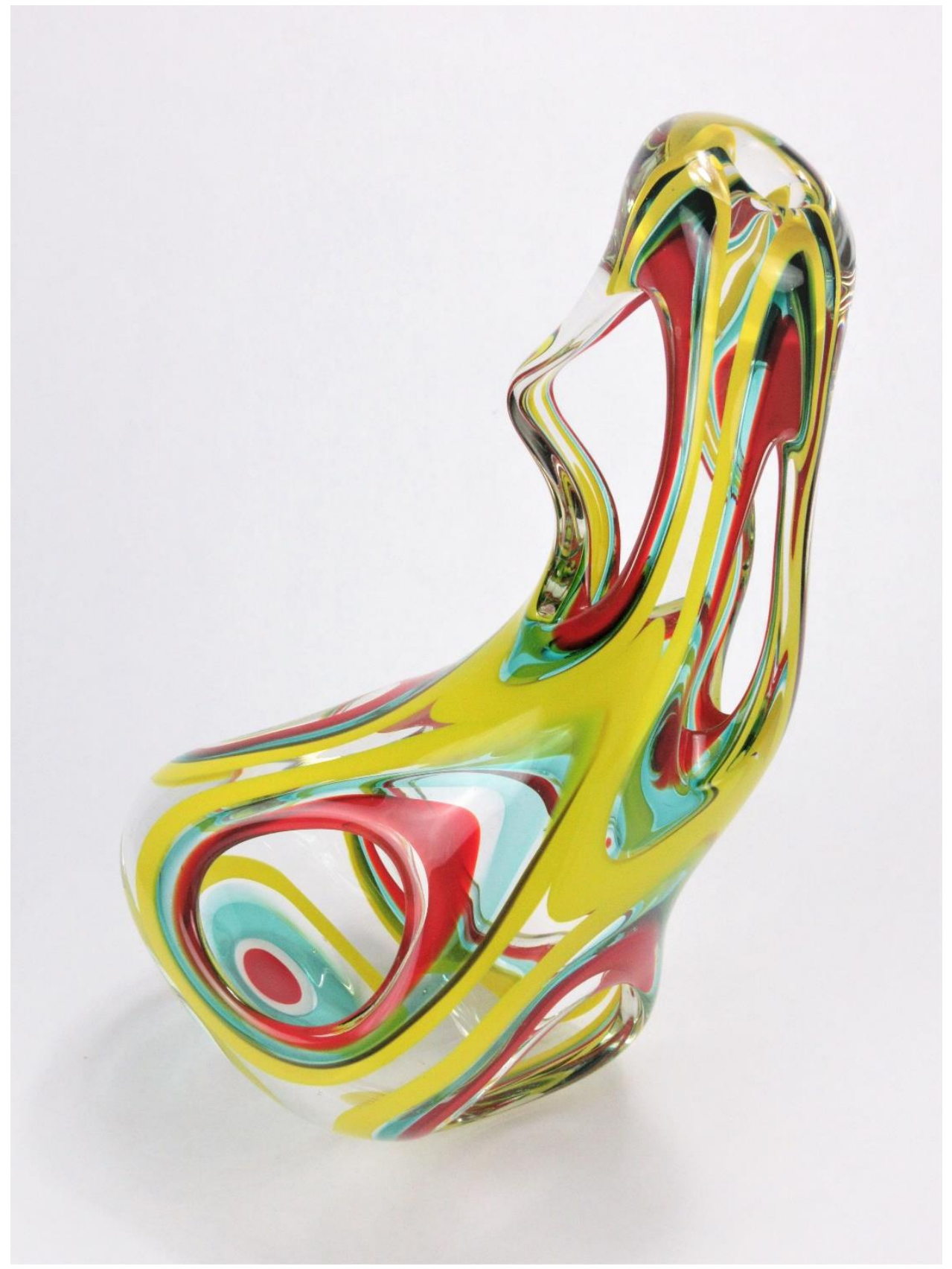

Figure 8. Concentric Dilation II, 2020, 17" x 12" x 8" 

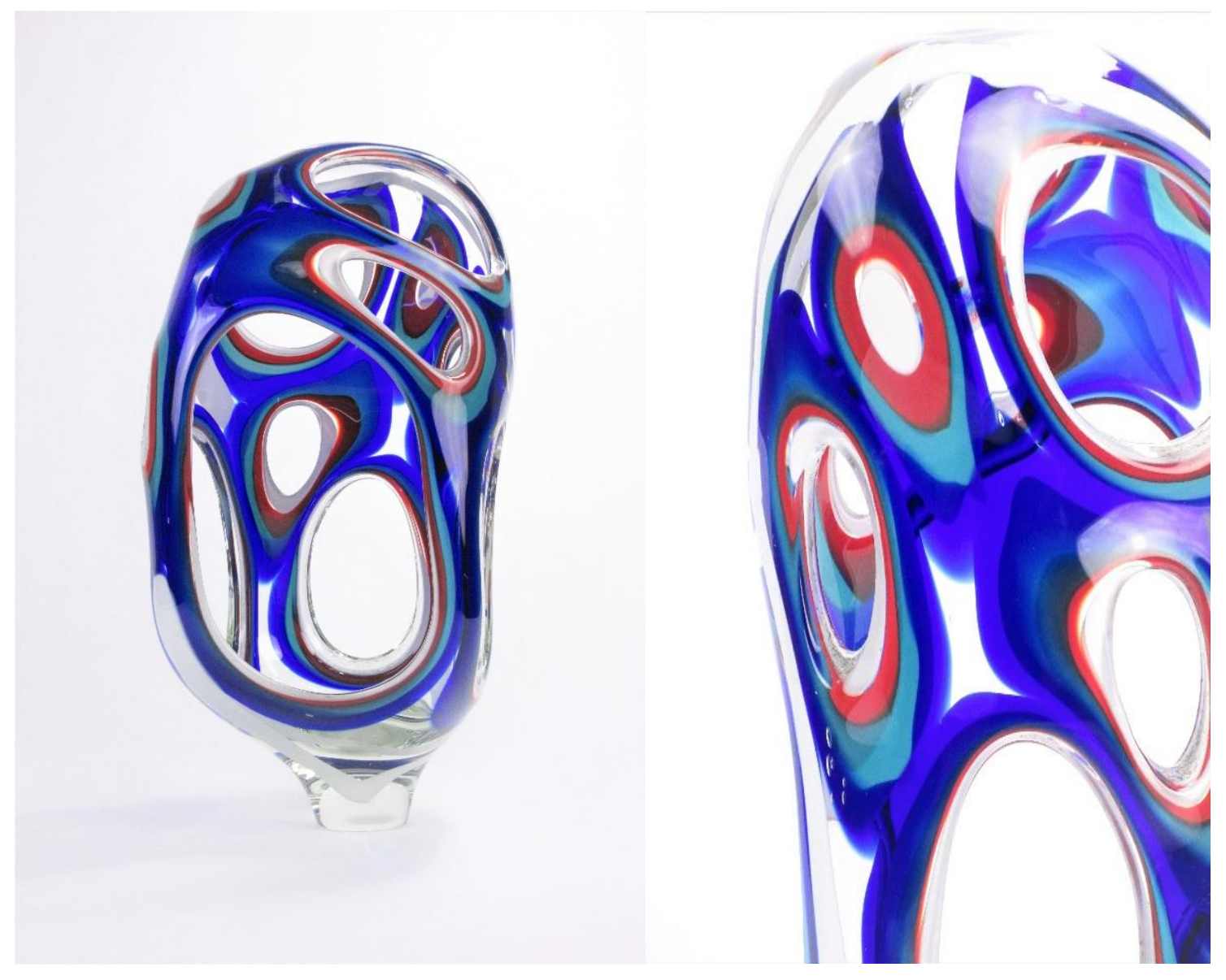

Figure 9. Concentric Dilation III, 2020, 16" x 8" x 11" 


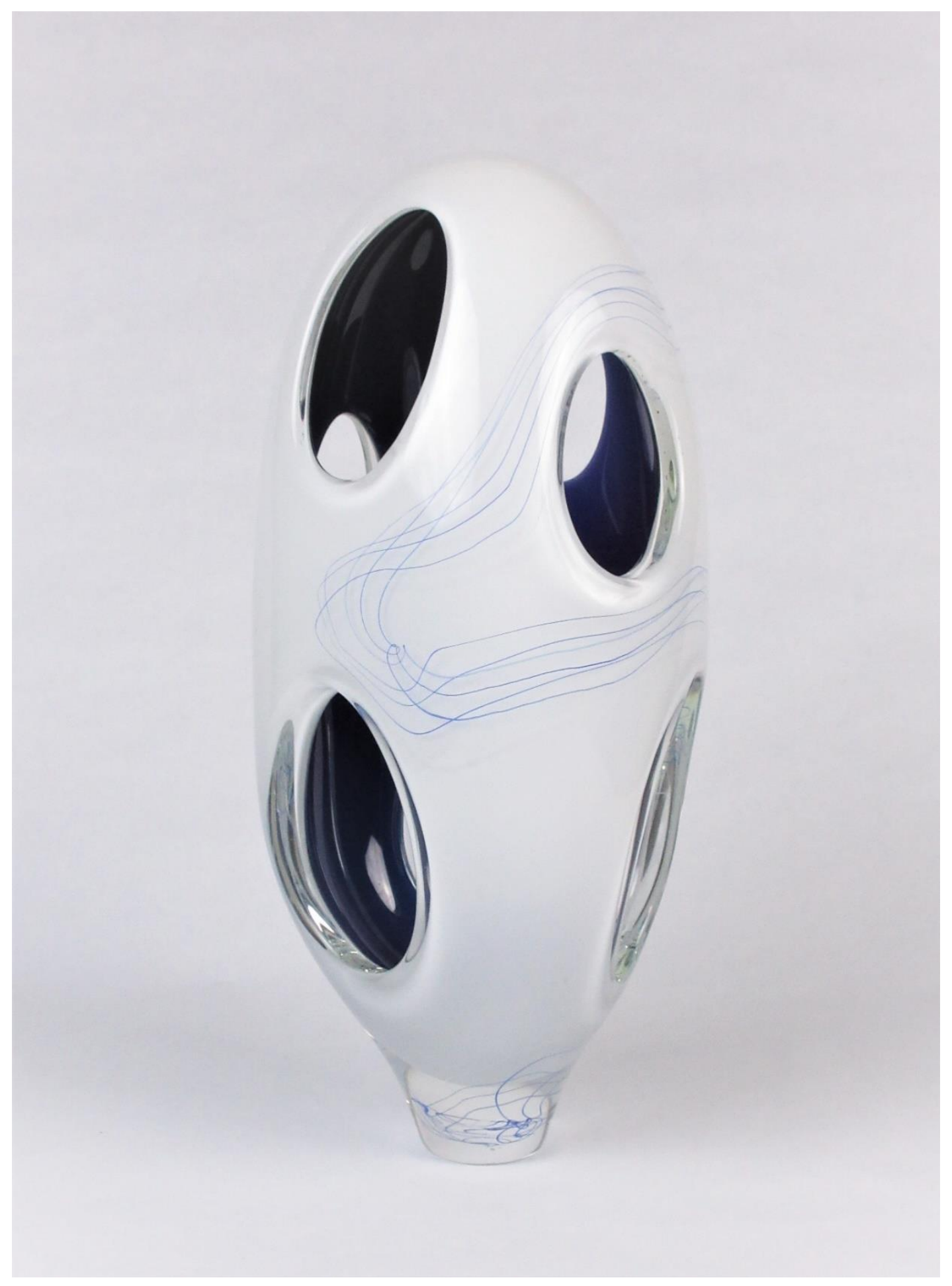

Figure 10. Wān yán, 2020, 16" x 10" x 9" 


\section{WORKS CITED}

Basener, William F. Topology and Its Applications. John Wiley \& Sons Inc, 2006.

Bill, Max, and Hüttinger Eduard. Max Bill. Rizzoli International Publications, Inc., 1978.

Bill, Max, and Margit Staber. Max Bill. Erker-Verlag, 1971.

Carter, J. Scott. How Surfaces Intersect in Space: an Introduction to Topology. World Scientific, 2006.

Carter, Ross, et al. "Pavement Cells and the Topology Puzzle." Development, Oxford University Press for The Company of Biologists Limited, 1 Dec. 2017, dev.biologists.org/content/144/23/4386.

Emmer, Michele. The Visual Mind: Art and Mathematics. MIT Press, 2005.

Fletcher, Angus. The Topological Imagination: Spheres, Edges, and Islands. Harvard University Press., 2016.

Martin, F. David. SCULPTURE AND ENLIVENED SPACE. UNIV. PR. OF KENTUCKY, 1981.

Samuel, Nina, and Mandelbrot Benoît B. The Islands of Benoît Mandelbrot: Fractals, Chaos, and the Materiality of Thinking ; Yale University Press, 2012.

Trier, Eduard, et al. Jean Arp: Sculpture, His Last Ten Years. H.N. Abrams, 1968. 